\title{
Invasive cystic hypersecretory carcinoma of the breast: a rare variant of breast cancer: $a$ case report and review of the literature
}

\author{
Jie Sun ${ }^{*}$, Xing Wang and Cuifang Wang
}

\begin{abstract}
Background: Cystic hypersecretory carcinoma is a rare subtype of breast cancer. It is a member of cystic hypersecretory lesions, which include a series of pathological disease lineages: cystic hypersecretory hyperplasia $(\mathrm{CHH}), \mathrm{CHH}$ with atypia, cystic hypersecretory carcinoma $(\mathrm{CHC})$ and invasive $\mathrm{CHC}$. It was found that most cystic hypersecretion lesions were in situ carcinoma, and only 19 cases of invasive cystic hypersecretion carcinoma were reported.

Case presentation: We are reporting a case of a 63-year-old female who had a lump in her left breast for 3 years. A modified radical mastectomy was done and morphological diagnosis of invasive CHC with axillary node metastasis was made.

Conclusions: Owing to a smaller number of reported cases, little is known about the biological behavior, prognosis and molecular study of cystic hypersecretion lesions. Therefore, more cases with follow-up data are needed to reveal the biological behavior of this rare tumor.
\end{abstract}

Keywords: Breast cancer, Cystic hypersecretory carcinoma, Cystic hypersecretory hyperplasia

\section{Introduction}

Cystic hypersecretory lesions of the breast have a spectrum of morphological features ranging from clearly benign $(\mathrm{CHH}), \mathrm{CHH}$ with atypia, cystic hypersecretory carcinoma $(\mathrm{CHC})$ to invasive $\mathrm{CHC}$ [1]. $\mathrm{CHC}$ was first described by Rosen PP and Scott M in 1984 [2]. The gross and microscopic features of this entity are unique. Gross detection shows numerous cysts of varying sizes. The contents of the cysts are gelatinous material. Microscopically, dilated ducts with marked secretory activity (the secretion is thyroid colloid-like substance) and lining by pseudostratified to micropapillary epithelium [1, 2]. Among the reported cases of cystic hypersecretory breast lesion, most cases are of in situ $\mathrm{CHC}$, with only a few cases of invasive $\mathrm{CHC}$. Invasion is suggested by solid nests structures and are usually poorly differentiated with no secretory characteristic. Extravasation of cyst material into the stroma does not indicate invasion $[1$,

\footnotetext{
* Correspondence: 1322957435@qq.com

Department of Pathology, Central Hospital affiliated to Shenyang Medical College, No 5, South Seven West Road, Tiexi District, Shenyang, Liaoning 110024, People's Republic of China
}

2]. This rare subtype of breast cancer was not included in 2012 WHO Classification of Tumors of the Breast,but its unique gross and microscopic features triggered us to report this rare tumor. Until now, only 19 cases of invasive $\mathrm{CHC}$ have been reported in the literature [1-11]. Our case is the twentieth case and the relevant literature is reviewed (Table 1).

\section{Case presentation}

A 63-year-old female presented with a palpable mass in her left breast for 3 years. The lump was gradually progressive in size for the past 3 years. Physical examination revealed a painless, ill-defined, hard, large mass with no nipple discharge in the upper outer quadrant of the left breast. Skin dimpling and ulceration were also seen. The patient had no past or family history of a breast disease. A modified radical mastectomy was performed. The CAF chemotherapy was administered after surgery.

Grossly, the left breast specimen showed an ill-defined, red gray, multiple nodular, $14 \times 12 \mathrm{~cm}$ tumor with surface skin ulceration [Fig. 1]. The cut surface revealed multiple cystic spaces filled with thick, gelatinous secretions and

(c) The Author(s). 2019 Open Access This article is distributed under the terms of the Creative Commons Attribution 4.0 International License (http://creativecommons.org/licenses/by/4.0/), which permits unrestricted use, distribution, and reproduction in any medium, provided you give appropriate credit to the original author(s) and the source, provide a link to the Creative Commons license, and indicate if changes were made. The Creative Commons Public Domain Dedication waiver (http://creativecommons.org/publicdomain/zero/1.0/) applies to the data made available in this article, unless otherwise stated. 
Table 1 Review of invasive CHCs in the literature

\begin{tabular}{|c|c|c|c|c|}
\hline Soure, y & Age, y & Type of Disease Present & Lymph Node Status & $E R / P R^{a}$ \\
\hline \multirow[t]{3}{*}{ Rosen and Scott [2], 1984} & 52 & Invasive & c & Pos/NA \\
\hline & 47 & Invasive & N1 & NA \\
\hline & 62 & invasive & NO & NA \\
\hline \multirow[t]{2}{*}{ Guerry et al. [1], 1988} & NA & Invasive & N1 & NA \\
\hline & NA & Invasive & c & NA \\
\hline Adams and Lacey [12], 1990 & 70 & Microinvasive & No & Neg/pos \\
\hline Kim et al. [3], 1997 & 37 & Invasive & NO & NA \\
\hline Herrmann et al. [4], 1999 & 49 & Invasive & NO & Pos/pos \\
\hline Lee JS [5], 2004 & 45 & Invasive & No & Neg/neg \\
\hline Shin SJ [6], 2004 & $42^{b}$ & Invasive & $N$ (micro) & NA \\
\hline Skalova A [7], 2005 (two cases) & $66.8^{b}$ & Invasive & NA & $\begin{array}{l}\text { One Case } \\
\text { Pos/pos }\end{array}$ \\
\hline Chen DB [13], 2010 & 44 & Microinvasive & NA & Pos/pos \\
\hline Song SW [8], 2011 & 43 & Invasive & NA & NA \\
\hline D'Alfonso TM [14], 2014 & $62.8^{b}$ & Microinvasive & NA & Pos/pos \\
\hline \multirow[t]{2}{*}{ Bi R [9], 2014} & 37 & Invasive & N1 & NA \\
\hline & 46 & Invasive & NA & NA \\
\hline Gupta P [10], 2014 & 57 & Invasive & No & Neg/neg \\
\hline Sahoo N [11], 2017 & 32 & Invasive & N1 & Neg/neg \\
\hline Present case & 63 & Invasive & N1 & Neg/neg \\
\hline
\end{tabular}

${ }^{\mathrm{a} E R / P R}$ indicates estrogen receptor/progesterone receptor; NA: not available; pos: positive; neg: negative;

$\mathrm{N}$ (micro): lymph node micrometastasis

${ }^{\mathrm{b}}$ Mean age

'Indicates cases with distal metastatic disease

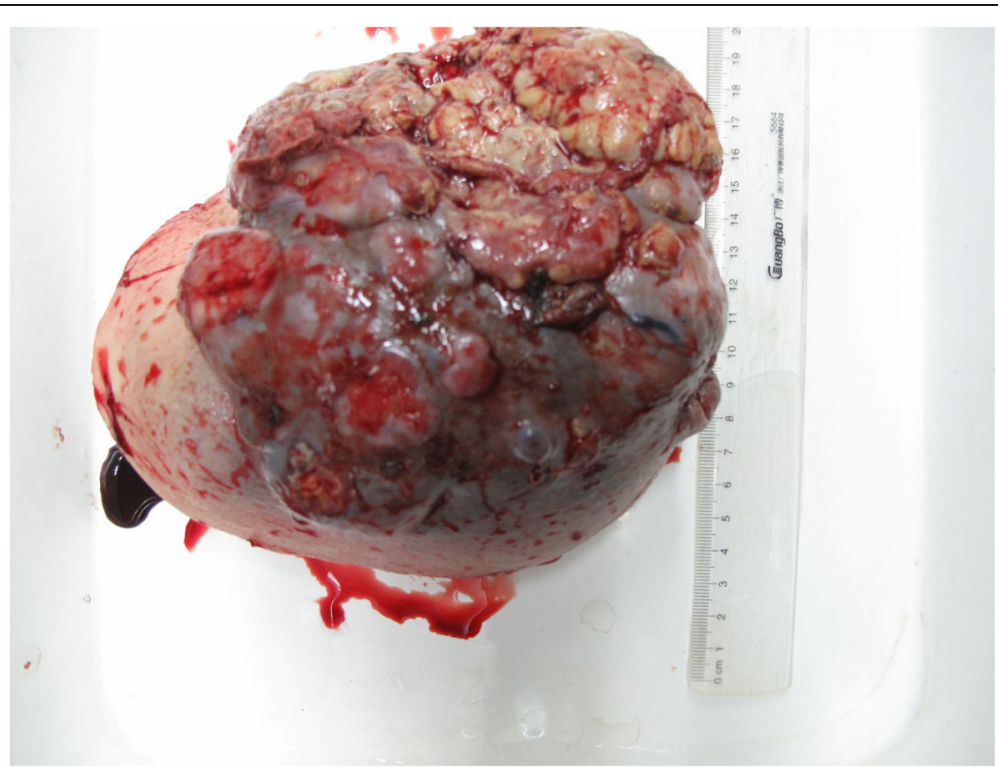

Fig. 1 The surface of the mass showing an ill-defined, red gray, multiple nodular, $14 \times 12 \mathrm{~cm}$ tumour with obvious skin ulceration 
gray-white solid areas. The individual cysts varied from 0.2 $\mathrm{cm}$ to $2.5 \mathrm{~cm}$ in dimension with cysts wall thickness from $0.1 \mathrm{~cm}$ to $0.5 \mathrm{~cm}$. Hemorrhage and necrosis was evident.

Microscopically, multiple variable-sized cystic spaces filled with thyroid colloid-like eosinophilic secretions [Fig. 2a] which was diastase resistant PAS positive and thyroglobulin negative. The eosinophilic secretions were retracted from the surrounding epithelia, producing scalloped margins. The cyst lining epithelium exhibited a variable pattern. In some areas the lining was flat to cuboidal epithelium and devoid of cellular atypia [Fig. 2b]. In other areas the epithelium showed a proliferative change in the form of pseudo stratification, knobby tufts [Fig. 2c], micropapillary [Fig. 2d] and cribriform [Fig. $2 \mathrm{e}$. An invasive component comprising of irregular neoplastic glands or nests was seen [Fig. 2f]. Eight axillary lymph nodes showed macro metastasis and cystic areas were also seen in the lymph node metastases [Fig. 3a]. Immunohistochemistry shows, the cystic contents were negative for thyroglobulin. Prognostic markers were ER negative, PR negative and HER2 3+. Ki67 was 30\% positive. A diagnosis of invasive $\mathrm{CHC}$ with axillary node metastasis was made.

\section{Discussion}

$\mathrm{CHC}$ is an uncommon subtype of duct carcinoma. The usual clinical presentation of $\mathrm{CHC}$ is a palpable lump and rarely nipple discharge. Calcification may be found in some cases by molybdenum target $\mathrm{x}$-ray [8]. The present case had a long onset time (3 years). The lump was gradually progressive in size with an obvious skin ulceration. Microscopically, all features of cystic hypersecretory lesions were observed, including $\mathrm{CHH}, \mathrm{CHC}$, and focal invasive carcinoma. Eight axillary lymph nodes showed macro metastasis. Metastatic foci had cystic foci that contained eosinophilic secretion. These indicate us that though $\mathrm{CHC}$ of the breast behaves in a low-grade fashion for many years, but, nevertheless, has a potential for invasive growth and development of distant metastasis. It is interesting that some pleomorphic tumor giant cells were seen in the lymph node metastases. The nuclear morphometry of the giant cell was bizarre, while the nucleus to cytoplasm ratio was normal and without nuclear mitosis [Fig. 3b]. The morphology of these cells was resemblance to degenerative cells. Ki67 was negative [Fig. 3c] and Her-2 3+ [Fig. 3d]. The patient was not received chemotherapy or radiation therapy before
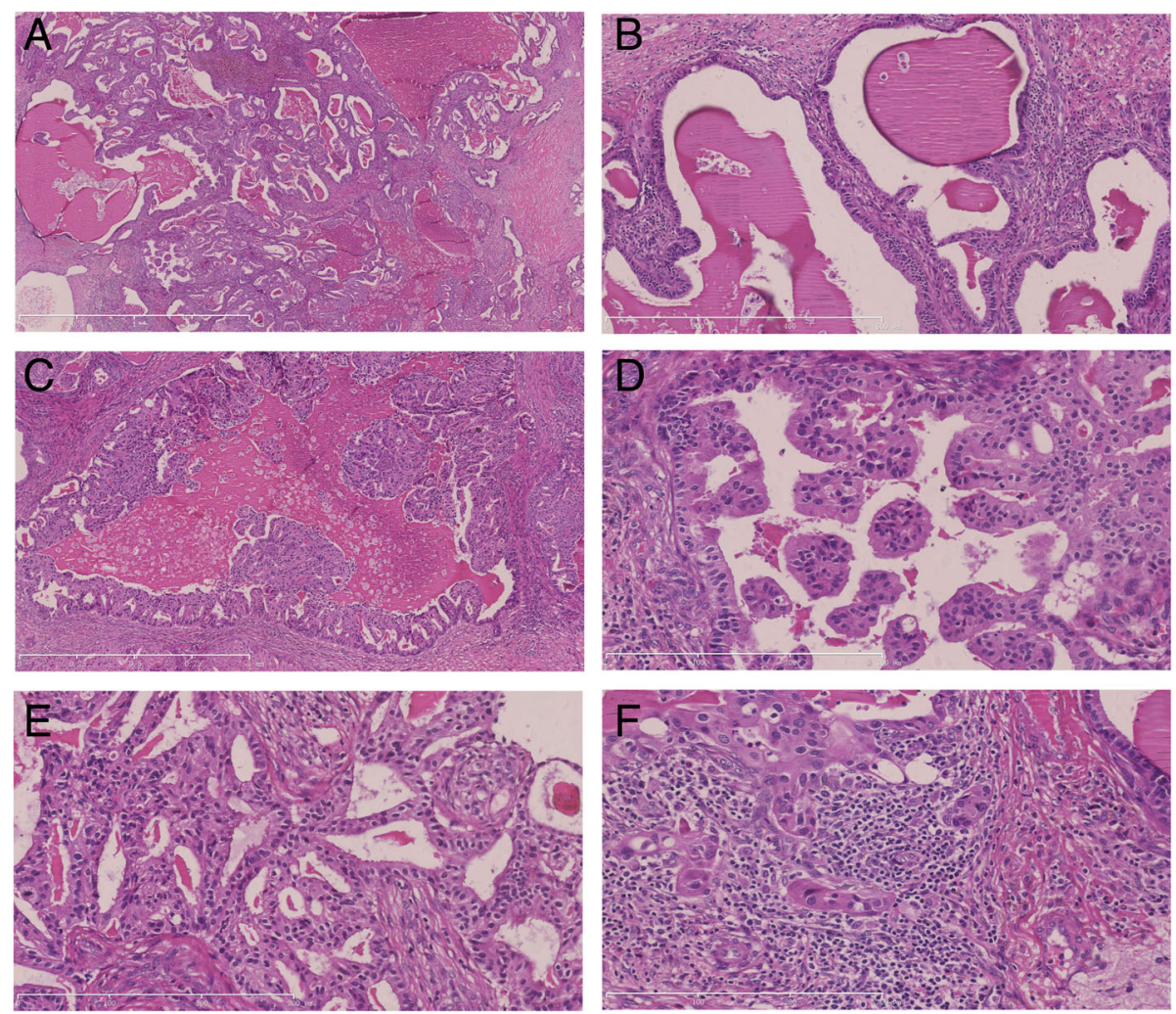

Fig. 2 Microscopic findings. Multiple variable-sized cysts and ducts filled with thyroid colloid-like eosinophilic secretions (a, H\&E, $\times 25)$. Some of the cysts are lined by flat to cuboidal epithelium $(\mathbf{b}, \mathrm{H \& E}, \times 100)$. In other areas the epithelium showed a proliferative change in the form of pseudostratification, knobby tufts $(\mathbf{c}, \mathrm{H} \& \mathrm{E}, \times 50)$, micropapillary $(\mathbf{d}, \mathrm{H} \& \mathrm{E}, \times 200)$ and cribriform $(\mathbf{e}, \mathrm{H} \& \mathrm{E}, \times 100)$. An invasive component comprising of solid nests was seen $(\mathbf{f}, \mathrm{H \& E}, \times 200)$ 

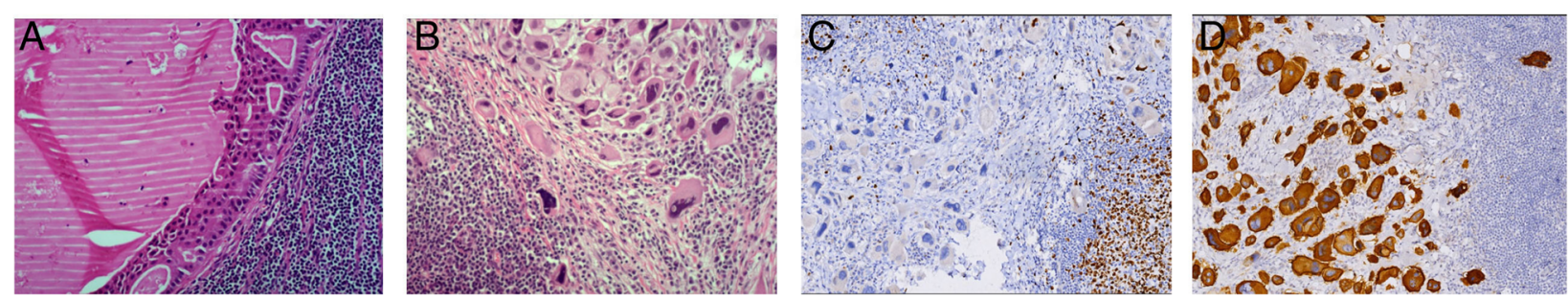

Fig. 3 Lymph node metastases. (a) Cystic areas in the lymph node metastases ( $H \& E, \times 400)$. (b) Pleomorphic tumor giant cells in the lymph node metastases $(H \& E, \times 400)$. (c) Negative reaction for Ki67 in pleomorphic tumor giant cells (Immunostaining, $\times 100)$. (d) Positive reaction for Her-2 in pleomorphic tumor giant cells (Immunostaining, $\times 100$ )

surgery, so we think that these degenerative cells may be spontaneous alternation of the tumor cells in the metastases.

The differential diagnosis of invasive $\mathrm{CHC}$ includes ductal carcinoma in situ (DCIS) with comedo necrosis, secretory carcinoma, mucocele-like lesion, and metastatic thyroid carcinoma. 1. DCIS with comedo necrosis: Grossly, DCIS with comedo necrosis showed an ill-defined, yellow-white, granular appearance. Comedo necrosis can be seen in the cut surface. Microscopically, dilated ducts filled with necrotic material instead of thyroid colloid-like eosinophilic secretions. 2. Secretory carcinoma: Secretory carcinoma is also known as "juvenile secretory carcinoma". It occurs most frequently in women of childbearing age with an average onset age of 25 years old. Secretory carcinoma contains a microcystic honeycomb appearance, eosinophilic secretion and vacuolar cytoplasm, while $\mathrm{CHC}$ is characterized by large dilated cystoid structures; 3. mucocele-like lesion: Grossly, mucocele-like lesion is similar to CHC. It also demonstrates cystically dilated ducts containing gelatinous or mucous material. Microscopically, secretions of the lesion are pale blue, basophilic and often accompanied by gross calcification, which are not typical features of CHC. 4. Metastatic thyroid carcinoma:Metastatic follicular thyroid cancer may resemble $\mathrm{CHC}$. Histological differentiation of these two lesions may require immunohistochemical staining of thyroglobulin. Negative reaction for thyroglobulin was observed in the cyst contents of our case.

\section{Conclusion}

Invasive cystic hypersecretory carcinoma is a rare subtype of breast cancer, characterized by the marked secretory activity of a thyroid colloid-like substance and cyst formation lined by pseudostratified to micropapillary epithelium along with foci of invasion. Owing to a smaller number of reported cases, little is known about the biological behavior, prognosis and molecular study of cystic hypersecretion lesions. Therefore, more cases with follow-up data are needed to reveal the biological behavior of this rare tumor.

\section{Abbreviations}

CHC: Cystic Hypersecretory Carcinoma; CHH: Cystic Hypersecretory Hyperplasia; DCIS: Ductal Carcinoma in Situ

\section{Acknowledgements}

Not applicable.

Funding

None.

Availability of data and materials

All relevant data are within the manuscript.

\section{Authors' contributions}

J S and CF W made the pathological diagnosis, as well as making a major contribution to the writing of the manuscript. X W made the pathology section and immunohistochemical staining, obtained written informed consent from the patient's son. All authors reviewed and approved of the final manuscript.

\section{Ethics approval and consent to participate}

Ethical approval for this report was obtained from the Research Ethics Committee, Central Hospital Affiliated to Shenyang Medical College,

Shenyang, China. Consent to participate was also obtained.

\section{Consent for publication}

Written informed consent for publication of this case was obtained from the patient's son. I obtained the consent for publication from the patient's son, rather than the patient herself because the patient had already passed away when I wrote this case report.

\section{Competing interests}

None of the authors have any competing interests.

\section{Publisher's Note}

Springer Nature remains neutral with regard to jurisdictional claims in published maps and institutional affiliations.

Received: 22 March 2018 Accepted: 28 December 2018 Published online: 08 January 2019

\section{References}

1. Guerry P, Erlandson RA, Rosen PP. Cystic hypersecretory hyperplasia and cystic hypersecretory duct carcinoma of the breast. Cancer. 1988;61:161120.

2. Rosen PP, Scott M. Cystic hypersecretory duct carcinoma of the breast. Am J Surg Pathol. 1984;8(1):31-41.

3. Kim MK, Kwon GY, Gong GY. Fine needle aspiration cytology of cystic hypersecretory carcinoma of the breast. A case report. Acta Cytol. 1997; 41(3):892-6.

4. Herrmann ME, McClatchey KD, Siziopikou KP. Invasive cystic hypersecretory ductal carcinoma of breast: a case report and review of the literature. Arch Pathol Lab Med. 1999;123(11):1108-10.

5. Lee JS, Lee YJ. Invasive cystic hypersecretory carcinoma of the breast: a case report. J Korean Med Sci. 2004;19(1):149-51. 
6. Shin SJ, Rosen PP. Carcinoma arising from preexisting pregnancy-like and cystic hypersecretory hyperplasia lesions of the breast: a clinicopathologic study of 9 patients. Am J Surg Pathol. 2004;28(6):789-93.

7. Skalova A, Ryska A, Kajo K, et al. Cystic hypersecretory carcinoma: rare and poorly recognized variant of intraductal carcinoma of the breast. Report of five cases. Histopathology. 2005;46(1):43-9.

8. Song SW, Whang IY, Chang ED. Cystic hypersecretory ductal carcinoma of the breast: a rare cause of cystic breast mass. Jpn J Radiol. 2011;29(9):660-2.

9. Bi R, Cheng Y, Yu B, et al. Clinicopathologic features of cystic hypersecretory lesion of the breast. Zhonghua Bing Li Xue Za Zhi. 2014;43(1):25-9.

10. Gupta P, Dhingra S, Musa O, et al. Invasive cystic hypersecretory carcinoma of the breast associated with papillary pattern: a rare and poorly recognised variant of ductal carcinoma of the breast. Ecancermedcalscience. 2014;8:477.

11. Sahoo N, Mishra P, Patra S, et al. Invasive cystic hypersecretory carcinoma of breast: a rare and under diagnosed variant of ductal carcinoma. J Clin Diagn Res. 2017;11(6):ED16-7.

12. Adams GD, Lacey S. Cystic hypersecretory breast carcinoma: an unusual breast cancer. Nebr Med J. 1990;75(5):104-8.

13. Chen DB, Kan X. Cystic hypersecretory carcinoma with microinvasive carcinoma and cystic hypersecretory hyperplasia of breast: report of a case. Zhonghua Bing Li Xue Za Zhi. 2010;39(1):54-5.

14. D'Alfonso TM, Ginter PS, Liu YF, et al. Cystic hypersecretory (in situ) carcinoma of the breast: a clinicopathologic and immunohistochemical characterization of 10 cases with clinical follow-up. Am J Surg Pathol. 2014; 38(1):45-53.

Ready to submit your research? Choose BMC and benefit from:

- fast, convenient online submission

- thorough peer review by experienced researchers in your field

- rapid publication on acceptance

- support for research data, including large and complex data types

- gold Open Access which fosters wider collaboration and increased citations

- maximum visibility for your research: over $100 \mathrm{M}$ website views per year

At $\mathrm{BMC}$, research is always in progress.

Learn more biomedcentral.com/submissions 